\title{
Microestrutura e resistência à corrosão de aços inoxidáveis supermartensíticos soldados por fricção radial
}

\author{
(Microstructure and corrosion resistance of radial friction welded supermartensitic stainless steels)
}

\author{
Carlos Alberto Della Rovere ${ }^{1}$, Celso Roberto Ribeiro ${ }^{1}$, Rodrigo da Silva ${ }^{1}$, Nelson Guedes de Alcântara ${ }^{1}$, Sebastião Elias Kuri ${ }^{1}$ \\ ${ }^{1}$ Universidade Federal de São Carlos, Departamento de Engenharia de Materiais - DEMa/UFSCar, São Carlos, SP, Brasil \\ carlosdrovere@ufscar.br
}

\begin{abstract}
Resumo
Neste trabalho, tubos de aço inoxidável supermartensítico (AISM) foram soldados por fricção radial (SFR) e suas propriedades de corrosão foram estudadas através de ensaios de polarização anódica em solução de 3,5\% de NaCl e da técnica eletroquímica de reativação potenciocinética de ciclo duplo (DL-EPR). As medidas foram realizadas em amostras extraídas de diferentes regiões da solda SFR, i.e., metal de base (MB), interface de soldagem e anel consumível (AC). As propriedades de corrosão foram discutidas em termos da microestrutura metalúrgica resultante em cada região. A precipitação de carbonetos de Cr que ocorre durante o tratamento de revenimento causa um empobrecimento em $\mathrm{Cr}$ substancial na estrutura revenida do $M B\left(I_{r} / I_{a}=54,22 \%\right)$. Por outro lado, as regiões do AC e da interface de soldagem, que tiveram suas microestruturas transformadas e seus precipitados de carboneto de Cr redissolvidos pelo ciclo termomecânico de soldagem SFR, apresentam um baixo grau de empobrecimento em $\mathrm{Cr}\left(\mathrm{I}_{r} \mathrm{I}_{a}<1 \%\right.$ ). A microestrutura do AC, composta de uma mistura de martensita temperada e austenita retida, apresenta maior resistência à corrosão localizada do que a estrutura revenida do $M B$. Também foi observado que a ferrita- $\delta$ diminui a resistência à corrosão por pites na região da interface de soldagem.
\end{abstract}

Palavras-chave: Aço inoxidável, Soldagem por fricção radial, Microestrutura, Corrosão, Técnicas eletroquímicas.

\begin{abstract}
In this work, supermartensitic stainless steel pipes were radial friction (RF) welded and their corrosion behavior were studied based on potentiodynamic polarization and double loop - electrochemical potentiokinetic reactivation (DL-EPR) tests. Measurements were performed on samples taken from the base metal (BM), weld interface, and consumable ring (CR) of the RF weldment. The corrosion properties were discussed in terms of their resulting metallurgical microstructure. The precipitation of Cr carbides that takes place during the tempering treatment induces a substantial $\mathrm{Cr}$ depletion value $\left(I_{r} I_{a}=54,22 \%\right)$. On the other hand, CR and weld interface regions, which had their microstructure transformed and their $\mathrm{Cr}$ carbide precipitates redissolved by the RF welding thermomechanical cycle, present a low level of $\mathrm{Cr}$ depletion $\left(I_{r} / I_{a}<1 \%\right)$. The AC microstructure, which is composed of a mixture of virgin martensite and stable retained austenite, presents an increase in pitting corrosion resistance compared to the tempered structure of the BM region. It was also observed that the $\delta$-ferrite decreases the pitting resistance of the weld interface region.
\end{abstract}

Key-words: Stainless steel, Radial Friction welding, Microstructure, Corrosion; Electrochemical techniques.

\section{Introdução}

Desde o início dos anos 90, a indústria de petróleo e gás tem promovido o desenvolvimento de novas ligas resistentes à corrosão para aplicações em tubulações onshore e offshore. Neste contexto, os aços inoxidáveis supermartensíticos (AISMs) foram introduzidos como uma alternativa prática e econômica aos aços carbono e aços inoxidáveis duplex para aplicações em poços de óleo e gás com condições corrosivas moderadas, pois como possuem melhor resistência à corrosão do que os aços carbono, não necessitam de revestimentos e inibidores e, além disso, seus custos de produção são inferiores aos dos inoxidáveis

Recebido em 16/06/2014, texto final em 12/09/2014.

DOI: http://dx.doi.org/10.1590/0104-9224/SI1903.08 duplex [1,2].

Hoje, os maiores desafios dos AISMs estão ligados a sua soldabilidade e ao desempenho mecânico e de corrosão do material soldado, bem como com o desenvolvimento de processos de soldagem rápidos, confiáveis e econômicos que minimizem ou até mesmo dispensem os caros e demorados tratamentos térmicos pós-soldagem. Neste contexto, processos novos e avançados têm sido investigados como alternativas aos processos de soldagem convencionais para os AISMs, tais como os processos de soldagem a laser e por feixe de elétrons, bem como um processo de soldagem no estado sólido conhecido como soldagem por fricção radial (SFR) [3-6]. Este é uma variante do processo de soldagem por fricção que foi desenvolvido pelo The Welding Institute (TWI) como uma técnica de junção one-shot para tubulações, oferecendo vantagens significativas sobre os processos de soldagem convencionais, por exemplo, um tempo de soldagem extremamente rápido, a ausência de necessidade 
de habilidades do operador, solda de alta qualidade, grande reprodutibilidade e a possibilidade de unir materiais dissimilares. Além disso, muitos dos problemas metalúrgicos associados aos processos de soldagem por fusão podem ser evitados, uma vez que a SFR é um processo de soldagem no estado sólido [5,6].

Apesar das vantagens citadas acima e do excelente potencial da SFR para unir tubulações offshore, este processo de soldagem no estado sólido ainda não é amplamente aplicado. Além disso, a literatura atual contém poucos estudos sobre a microestrutura e a resistência à corrosão de tubos soldados por SFR, portanto estudos adicionais são de importância vital para o avanço no desenvolvimento deste processo e para expandir sua aplicação industrial. Neste estudo, a resistência à corrosão e as características microestruturais das diferentes regiões que se desenvolvem em tubos de AISMs soldados por SFR são estudadas separadamente, i.e., metal de base, anel consumível e interface de soldagem. A resistência à corrosão foi estudada através de ensaios de polarização anódica e da técnica eletroquímica de reativação potenciocinética de ciclo duplo (DL-EPR). As microestruturas resultantes foram analisadas por microscopia óptica (MO), microscopia eletrônica de varredura (MEV) e difração de raios-X (DRX).

\section{Materiais e Métodos}

Os segmentos de tubos de AISMs soldados por SFR tinham um diâmetro externo de 168,3 mm e uma espessura de parede de 14,3 mm. As soldas foram produzidas usando um anel consumível (AC) usinado a partir de um tubo com espessura de parede maior. O material da tubulação e do AC consistia de um AISM alta liga (12,01 \%Cr, 6,4 \%Ni, 2,42 \%Mo, 0,47 $\% \mathrm{Mn}, 0,17 \% \mathrm{Si}, 0,10 \% \mathrm{Ti}, 0,01 \% \mathrm{C}$ - porcentagem em peso) na condição temperado e revenido.

O processo SFR é executado juntando-se dois tubos chanfrados, que são fixados com abraçadeiras para evitar qualquer movimento axial ou rotação adicional. Um AC do mesmo material dos tubos é colocado entre as extremidades dos dois tubos, conforme ilustrado na Figura 1 (a). Este AC é então rotacionado e comprimido radialmente para produzir calor de

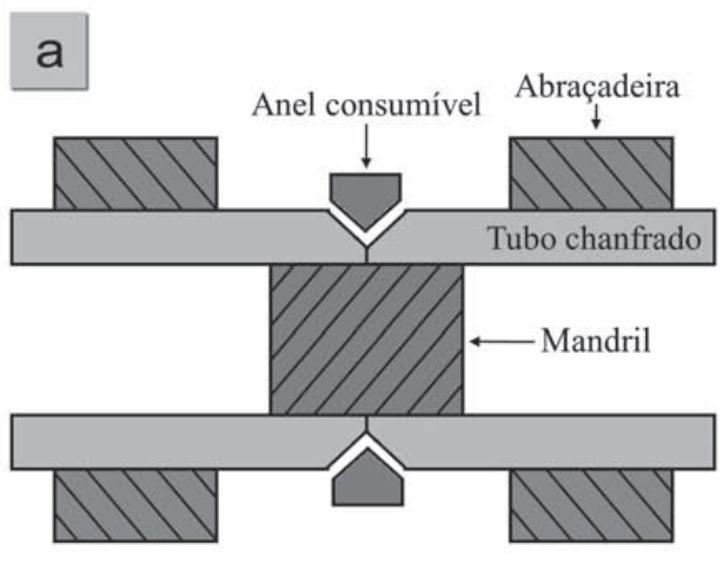

fricção, que por sua vez irá gerar as condições termomecânicas necessárias para formar a solda [Figura 1 (b)]. Para contrapor a pressão de soldagem radial e manter as extremidades dos tubos alinhadas radialmente, um mandril resistente ao calor é simultaneamente expandido dentro da tubulação no local da solda. Após um determinado período de tempo e um nível controlado de deslocamento de metal (chamado burn-off), a rotação é interrompida e a pressão radial é mantida ou aumentada para consolidar a solda [5-7].

A Tabela 1 lista os parâmetros de soldagem utilizados neste trabalho. Mais detalhes sobre o processo SFR, a otimização dos parâmetros e propriedades mecânicas de tubos de AISMs soldados por SFR podem ser encontrados na literatura [5-7]. É interessante ressaltar que os tubos soldados por SFR não foram submetidos a um tratamento térmico pós-soldagem e todas as análises foram realizadas na condição como soldado.

A Figura 2 (a) mostra uma macrografia dos tubos de AISMs soldados por SFR, onde pode ser visto claramente as três regiões distintas da solda SFR: metal de base (MB), AC e interface de soldagem. Nesta figura, também está ilustrado os locais onde as amostras cilíndricas $(\square=5 \mathrm{~mm}$ ) foram cuidadosamente extraídas por eletroerosão (círculos tracejados). Além disso, conforme mostrado em maior detalhe na Figura 2 (b), nota-se que a região da interface de soldagem é composta por duas subregiões: (1) a zona termicamente afetada (ZTA) e (2) a zona termomecanicamente afetada (ZTMA).

Tabela 1. Parâmetros de soldagem utilizados durante o processo de soldagem por fricção radial (SFR).

\begin{tabular}{|c|c|}
\hline Parâmetro & valor \\
\hline Velocidade de fricção (rpm) & 200 \\
\hline Pressão de fricção (MPa) & 4 \\
\hline Tempo de fricção (s) & 24 \\
\hline Distância de burn-off (m) & $7,5 \times 10^{-3}$ \\
\hline Tempo de frenagem (s) & 1 \\
\hline Pressão de forjamento (MPa) & 4 \\
\hline Tempo de forjamento (s) & 4 \\
\hline
\end{tabular}

b

Tubo fixado com abraçadeiras

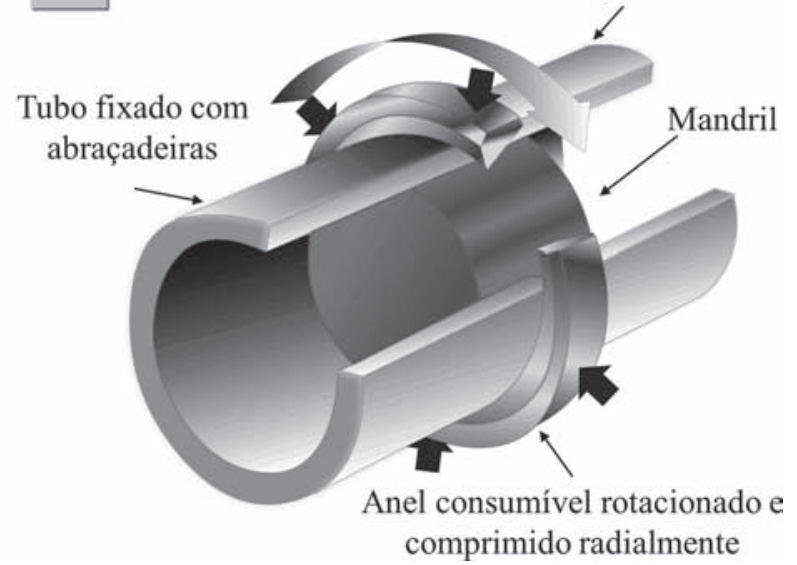

Figura 1. Vistas esquemáticas do processo de soldagem por fricção radial (SFR). 

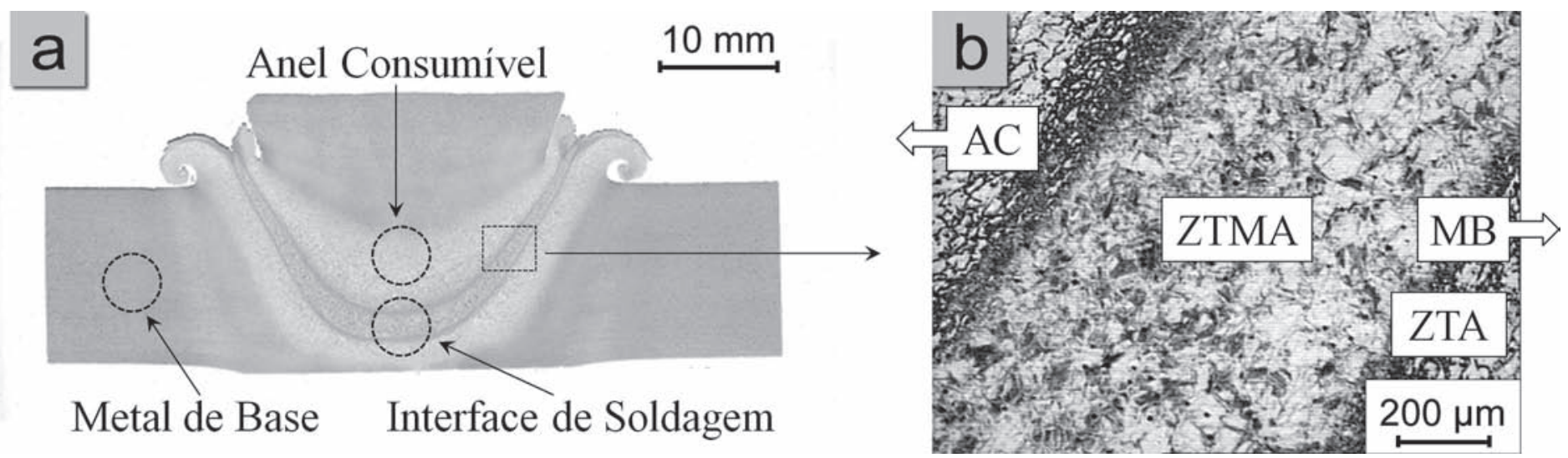

Figura 2. (a) Macrografia dos tubos de AISMs soldados por SFR, mostrando os locais onde as amostras estudadas foram extraídas (círculos tracejados); (b) micrografia ótica detalhando as características microestruturais da região da interface da soldagem.

A microestrutura das regiões $\mathrm{MB}$, AC e interface de soldagem foram analisadas por MO e DRX. Para determinar as fases presentes nas três regiões da solda SFR e suas quantidades relativas, os espectros de DRX foram refinados pelo método de Rietveld através do software Maud [8].

$\mathrm{Na}$ realização dos ensaios eletroquímicos utilizou-se uma célula eletroquímica convencional de três eletrodos, com eletrodo auxiliar de platina e eletrodo de referência de calomelano saturado (ECS). Os eletrodos de trabalho foram construídos com as amostras cilíndricas citadas acima (área exposta de $0,196 \mathrm{~cm}^{2}$ ). Os ensaios foram realizados em soluções naturalmente aeradas e em temperaturas próximas a $25^{\circ} \mathrm{C}$. Foram feitas, no mínimo, cinco medidas para cada eletrodo de trabalho para garantir uma boa reprodutibilidade e os valores médios foram considerados.

Para medir o grau de empobrecimento em cromo (Cr) ao longo das diferentes regiões da solda, um ensaio de DL-EPR foi realizado em uma solução $0,5 \mathrm{~mol} / \mathrm{L}$ de ácido sulfúrico $\left(\mathrm{H}_{2} \mathrm{SO}_{4}\right)+0,01 \mathrm{~mol} / \mathrm{L}$ de tiocianato de potássio (KSCN) [9]. A varredura de potenciais foi iniciada 15 minutos após a imersão das amostras. O potencial foi varrido na direção anódica de $-400 \mathrm{mV}$ (ECS) para $600 \mathrm{mV}$ (ECS), em seguida, a varredura de potenciais foi revertida para o sentido catódico até $-400 \mathrm{mV}$ (ECS). Utilizou-se uma taxa de varredura de $1,67 \mathrm{mV} / \mathrm{s}$. A perda de resistência à corrosão devido às regiões empobrecidas em $\mathrm{Cr}$ foi avaliada em termos da relação dos picos de corrente $I_{r} / I_{a} \mathrm{x}$ 100 em combinação com a observação da microestrutura por meio de MEV após as medidas. O valor de $I_{a}$ foi obtido a partir da curva de polarização na direção anódica e está diretamente ligado com a dissolução de toda a superfície da amostra, enquanto o de $I_{r}$ está associado às regiões empobrecidas em $\mathrm{Cr}$ suscetíveis à corrosão e seu valor é obtido a partir da curva de polarização na direção catódica [9].

Para determinação do potencial de pites $\left(\mathrm{E}_{\mathrm{PITE}}\right)$ nas diferentes regiões da solda, foram realizados ensaios de polarização anódica em solução de 3,5\% de cloreto de sódio $(\mathrm{NaCl})$. As medidas foram programadas para iniciarem após 60 minutos de estabilização no potencial de circuito aberto. Este potencial de início das medidas foi definido como o potencial de corrosão (Ecorr). As curvas de polarização anódica foram feitas com velocidades de varredura de $1 \mathrm{mV} / \mathrm{s}$, partindo-se do Ecorr até que a densidade de corrente atingisse $5 \times 10^{-4} \mathrm{~A} / \mathrm{cm}^{2}$. Os valores de Epite foram tomados como o potencial onde ocorreu um aumento brusco e repentino da densidade de corrente, excedendo o valor de $200 \mu \mathrm{A} / \mathrm{cm}^{2}$ [10]. Os locais preferenciais de nucleação e a morfologia dos pites após os ensaios de polarização foram observadas por MEV.

\section{Resultados e Discussão}

A Figura 3 apresenta as microestruturas características do MB, AC e da interface de soldagem. Nota-se que a martensita revenida é a principal fase presente no MB [Figura 3 (a)]. Além disso, de acordo com o refinamento de Rietveld aplicado aos espectros de DRX (Figura 4), a estrutura do MB também possui uma fração volumétrica de austenita retida $(\mathrm{V} \gamma)$ que está em torno de 0,122 . Essa austenita está finamente distribuída entre as ripas de martensita e é detectável apenas por meio de microscopia de alta resolução [11]. No AC [Figura 3 (b)], observa-se que uma microestrutura refinada, composta de uma mistura de martensita temperada e austenita retida $(\mathrm{V} \gamma=0,121)$, se formou devido ao ciclo térmico de soldagem. Por outro lado, o calor e a deformação gerada durante o processo SFR produziram duas zonas distintas na interface de soldagem: (1) uma zona termomecanicamente afetada (ZTMA) localizada na interface de fricção, onde o material foi submetido a uma deformação plástica elevada devido à pressão compressiva aplicada para consolidar a união metalúrgica, além das alterações microestruturais induzidas pelo calor; e (2) uma zona termicamente afetada (ZTA), onde a microestrutura do material foi modificada principalmente pelo ciclo térmico do processo de soldagem. Como indicado na Figura 3 (c) e (d), a microestrutura da ZTA consiste predominantemente de martensita temperada e ferrita- $\delta$ retida ao longo dos contornos de grão, enquanto a ZTMA apresenta uma microestrutura com grãos mais grossos, composta de martensita temperada e uma pequena fração de ferrita- $\delta[5,12]$. Os espectros de DRX indicam que a interface de soldagem não apresenta nenhuma austenita retida. Uma discussão mais detalhada sobre a evolução microestrutural de um AISM durante o processo SFR é apresentada em um trabalho anterior [5]. 

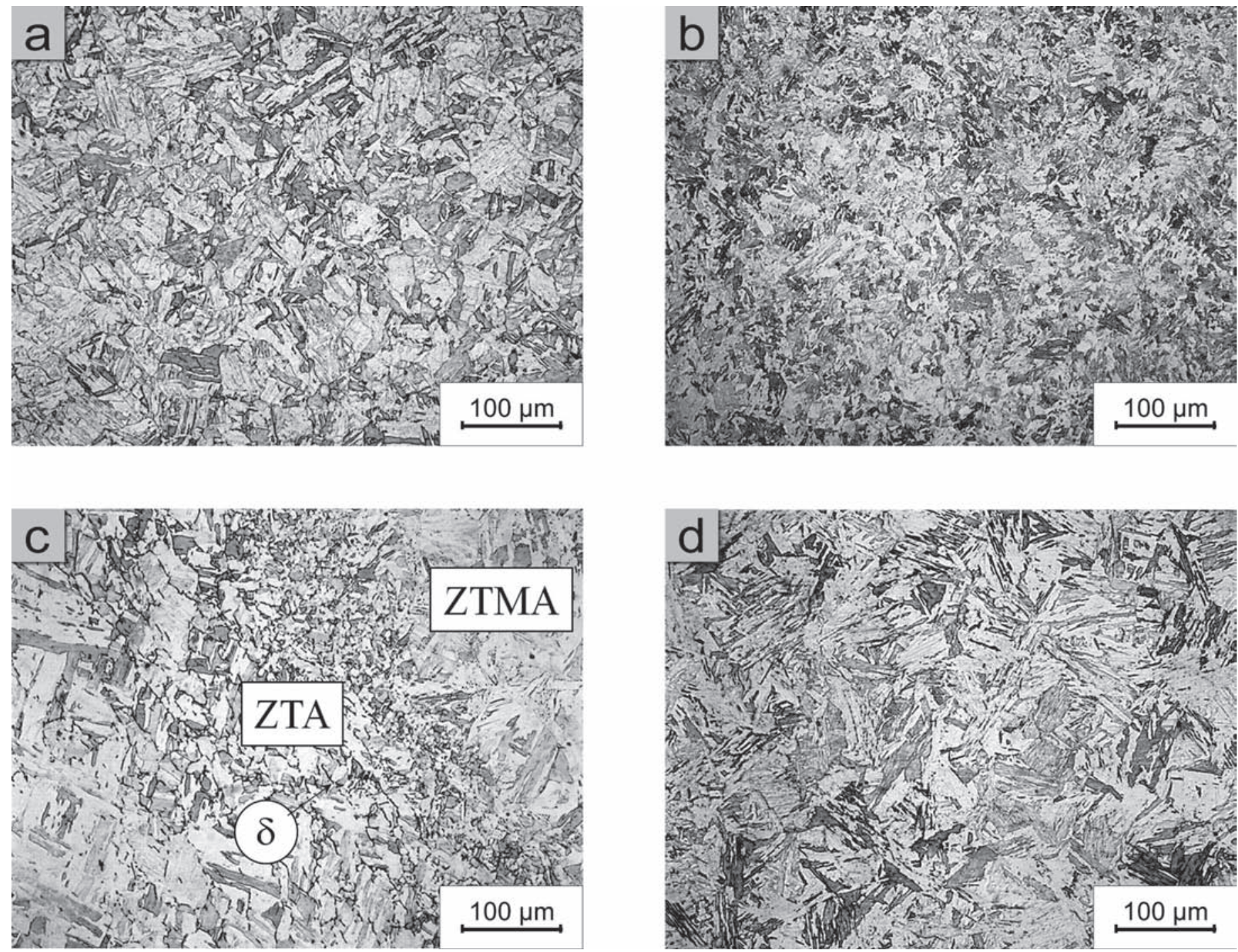

Figura 3. Microestrutura típica das diferentes regiões presentes na solda SFR: (a) MB; (b) AC; (c) ZTA e (d) ZTMA.

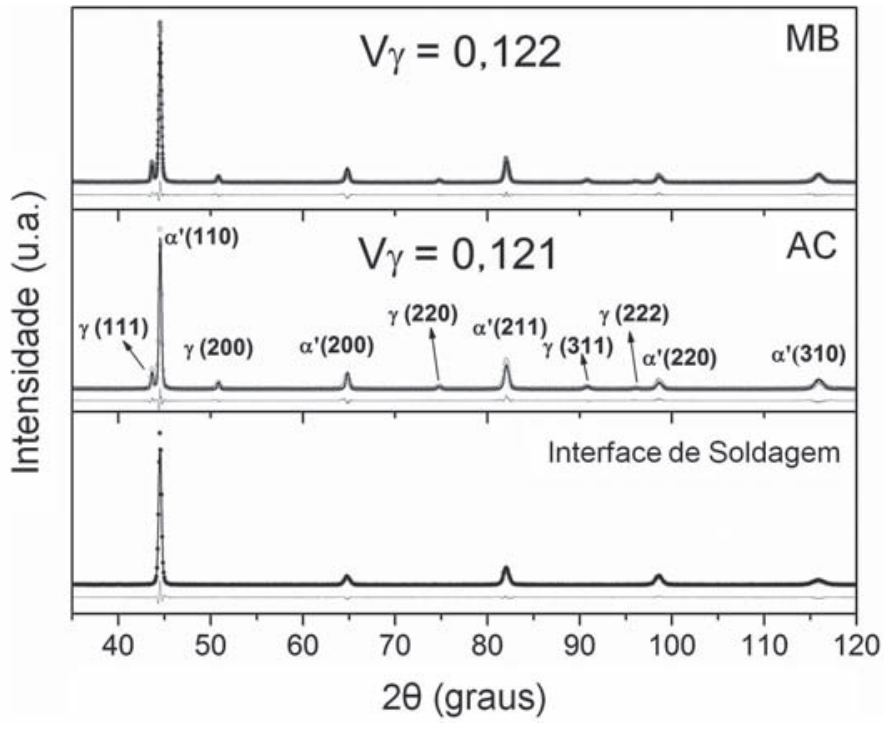

Figura 4. Espectros de DRX das diferentes regiões da solda SFR.
Medidas de DL-EPR em solução 0,5 mol/L de $\mathrm{H}_{2} \mathrm{SO}_{4}+0,01$ $\mathrm{mol} / \mathrm{L}$ de $\mathrm{KSCN}$ a $25^{\circ} \mathrm{C}$ foram realizadas para avaliar o grau de empobrecimento em $\mathrm{Cr}$ ao longo das diferentes regiões da solda SFR. A Figura 5 mostra as curvas de DL-EPR obtidas para o MB, AC e interface de soldagem. Nota-se que a curva do MB apresentou um pico de densidade de corrente de reativação bastante amplo, enquanto nenhum pico de densidade de corrente de reativação foi observado no AC. Já na curva da interface de soldagem, um pico de reativação pequeno pode ser verificado na varredura catódica [Figura 5 (c)]. A origem do pico reativação nas curvas do MB e da interface de soldagem será discutida abaixo.

O grau de perda de resistência à corrosão $\left(I / I_{a}\right)$ nas amostras extraídas das diferentes regiões dos tubos de AISMs soldados por SFR é mostrado na Figura 5 (d). Nota-se que a relação $I_{r}$ ! $I_{a}$ para o MB é muito maior do que para o AC e interface de soldagem, o que indica que o grau de empobrecimento em $\mathrm{Cr}$ do MB é maior do que nas outras regiões da solda SFR. Esse comportamento pode ser explicado da seguinte maneira: devido 

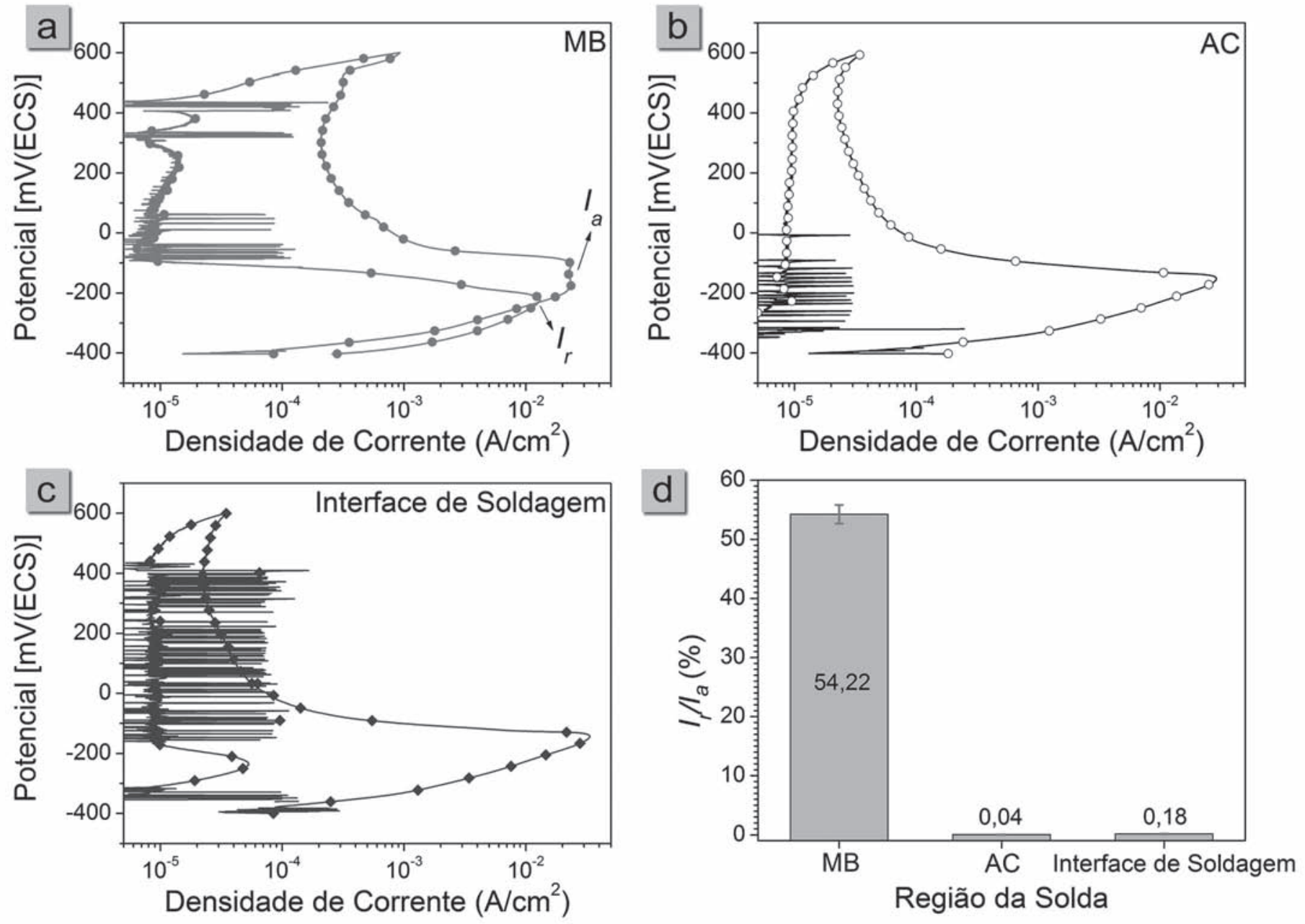

Figura 5. Curvas de DL-EPR das diferentes regiões da solda SFR: (a) MB; (b) AC; (c) interface de soldagem e (d) relação $I_{r} / I_{a}$.

ao baixo teor de carbono, os AISMs apresentam uma tendência menor de precipitar carbonetos de $\mathrm{Cr}$ do que os aços inoxidáveis convencionais. Nos AISMs, os átomos de C estão completamente dissolvidos na matriz austenítica em temperaturas elevada e este estado é mantido durante a transformação da austenita para martensita pela têmpera. No entanto, durante o tratamento térmico de revenimento, os átomos de $\mathrm{C}$ em solução sólida se combinam com os de $\mathrm{Cr}$ para formar carbonetos de $\mathrm{Cr}$ (do tipo $\mathrm{M}_{23} \mathrm{C}_{6}$ ), tanto nos contornos como no interior dos grãos, produzindo, na maioria dos casos, um empobrecimento generalizado de $\mathrm{Cr}$ [1317]. Por esta razão, a estrutura revenida do MB apresenta um maior grau de perda de resistência à corrosão $\left(I_{r} / I_{a}\right)$ em relação às outras regiões da solda SFR (AC e interface de soldagem), que tiveram suas microestruturas transformadas e parte de seus precipitados de carboneto $\mathrm{Cr}$ redissolvidos pelo ciclo termomecânico do processo SFR.

Para identificar a morfologia do processo corrosivo, análises por meio de MEV do aspecto superficial das amostras foram realizadas após os testes de DL-EPR. Como pode ser visto na Figura 6 (a) e (b), um ataque bastante acentuado é observado tanto nos contornos de grão como entre as ripas de martensita no $\mathrm{MB}$, enquanto nenhum ataque significativo é observado na microestrutura do AC. Por outro lado, apesar do baixo valor da relação $I_{r} / I_{a}$ apresentada pela amostra extraída da interface da soldagem (que compreende as regiões ZTMA e ZTA), um ataque pronunciado pode ser claramente observado nos contornos de fase martensita/ferrita- $\delta$ na ZTA [Figura 6 (c)]. De acordo com a literatura [18-21], esta dissolução seletiva dos contornos de fase martensita/ferrita- $\delta$ pode ser relacionada a dois fatores: (1) a existência de regiões empobrecidas em $\mathrm{Cr}$ devido à precipitação de carbonetos de $\mathrm{Cr}$ (ou carbonitretos) próximo ao contorno da ferrita- $\delta$; e/ou (2) como a ferrita- $\delta$ é enriquecida em elementos ferritizantes (Cr, Mo, Si etc), sua formação durante o ciclo de soldagem pode levar a uma diminuição do teor de $\mathrm{Cr}$ na matriz metálica adjacente. O surgimento de um pequeno pico de reativação na varredura catódica da amostra da interface de soldagem parece estar diretamente associado ao ataque seletivo das interfaces martensita/ferrita- $\delta$ na ZTA. A baixa intensidade deste pico de reativação está relacionada com o tamanho relativamente pequeno das interfaces empobrecidas em $\mathrm{Cr}$ em comparação com a área total exposta da amostra.

Os ensaios de polarização anódica em solução 3,5\% de $\mathrm{NaCl}$ foram realizados para avaliar a resistência à corrosão localizada nas diferentes regiões dos tubos de AISMs soldados por SFR. A 
Figura 7 (a) mostra as curvas típicas obtidas para o MB, AC e interface de soldagem. Nota-se que as três regiões apresentam um comportamento anódico semelhante, mas com diferentes valores de $\mathrm{E}_{\text {PITE }}$. $\mathrm{O}$ valor de Ecorr de todas as amostras foi de aproximadamente -150 mV (ECS) e nenhuma das curvas exibiu um comportamento de transição ativo-passivo, indicando que as amostras já estavam no estado passivo no eletrólito. A densidade de corrente passiva também foi de aproximadamente $2 \mu \mathrm{A} /$ $\mathrm{cm}^{2}$ para todas as amostras. Além disso, algumas oscilações de corrente devido à nucleação de pites metaestáveis podem ser observadas com o aumento do potencial. Os valores de $\mathrm{E}_{\text {PITE }}$ obtidos a partir das curvas são apresentados na Figura 7 (b). Observa-se que a microestrutura do AC possui o maior valor de $\mathrm{E}_{\text {PITE }}[241,3 \mathrm{mV}(\mathrm{ECS})]$, indicando que esta região possui a maior resistência à corrosão localizada. As amostras do MB e interface de soldagem apresentam valores de $\mathrm{E}_{\mathrm{PITE}}$ de $218,8 \mathrm{mV}$ (ECS) e 210,3 mV (ECS), respectivamente.

As mudanças microestruturais promovidas pelo ciclo térmico do processo SFR levaram a um aumento da resistência à corrosão localizada na região do AC em comparação com a estrutura revenida da região do $\mathrm{MB}$. O melhor desempenho do AC pode ser atribuído à redissolução dos precipitados de
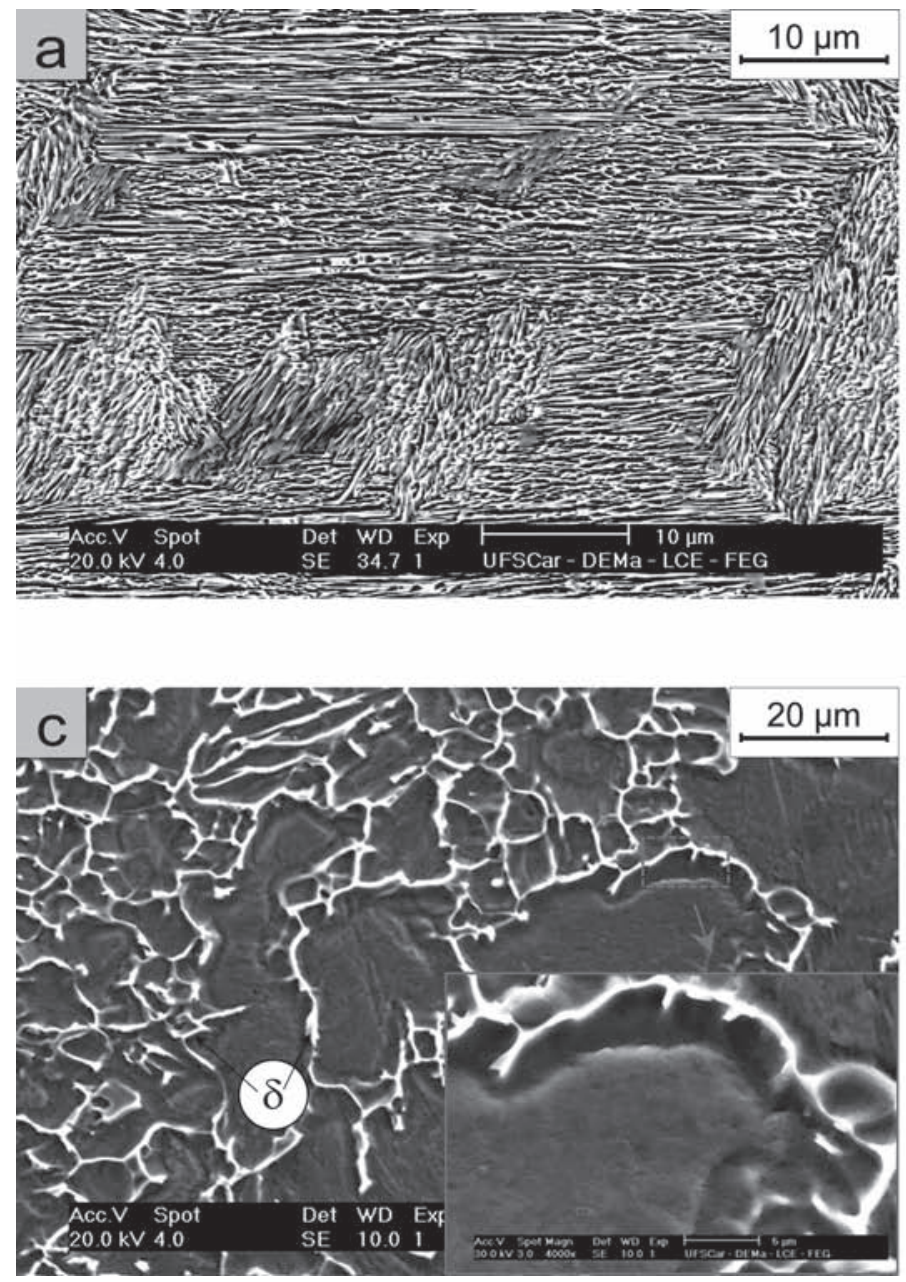

carbonetos de $\mathrm{Cr}$ e à formação de uma microestrutura refinada, composta por uma mistura de martensita temperada e austenita retida. Por outro lado, embora a redissolução dos precipitados de carbonetos de Cr também tenha ocorrido na interface de soldagem, fato que deveria melhorar a resistência à corrosão localizada desta região, a formação de ferrita- $\delta$ e sua retenção na microestrutura parecem ter sobrepujado o efeito benéfico da redissolução dos carbonetos e isto resultou em uma diminuição da resistência à corrosão localizada por pites. Hara e Asahi [18] também reportaram uma diminuição da resistência à corrosão localizada de um AISM devido à formação de ferrita- $\delta$.

Para identificar os locais preferenciais de nucleação dos pites, a superfície das amostras foram examinadas por MEV após os ensaios de polarização anódica em solução 3,5\% de $\mathrm{NaCl}$. A Figura 8 apresenta as imagens de MEV das amostras MB, AC e interface de soldagem após o ensaio de polarização. No MB e AC [Figuras 8 (a) e (b)], devido à microestrutura homogênea presente nestas regiões, os pites nuclearam e cresceram aleatoriamente por toda a superfície. Por outro lado, na amostra extraída da interface de soldagem, observou-se que a maioria dos pites nuclearam preferencialmente na martensita adjacente à ferrita- $\delta$ na ZTA [Figura 8 (c)]. Essa nucleação preferencial
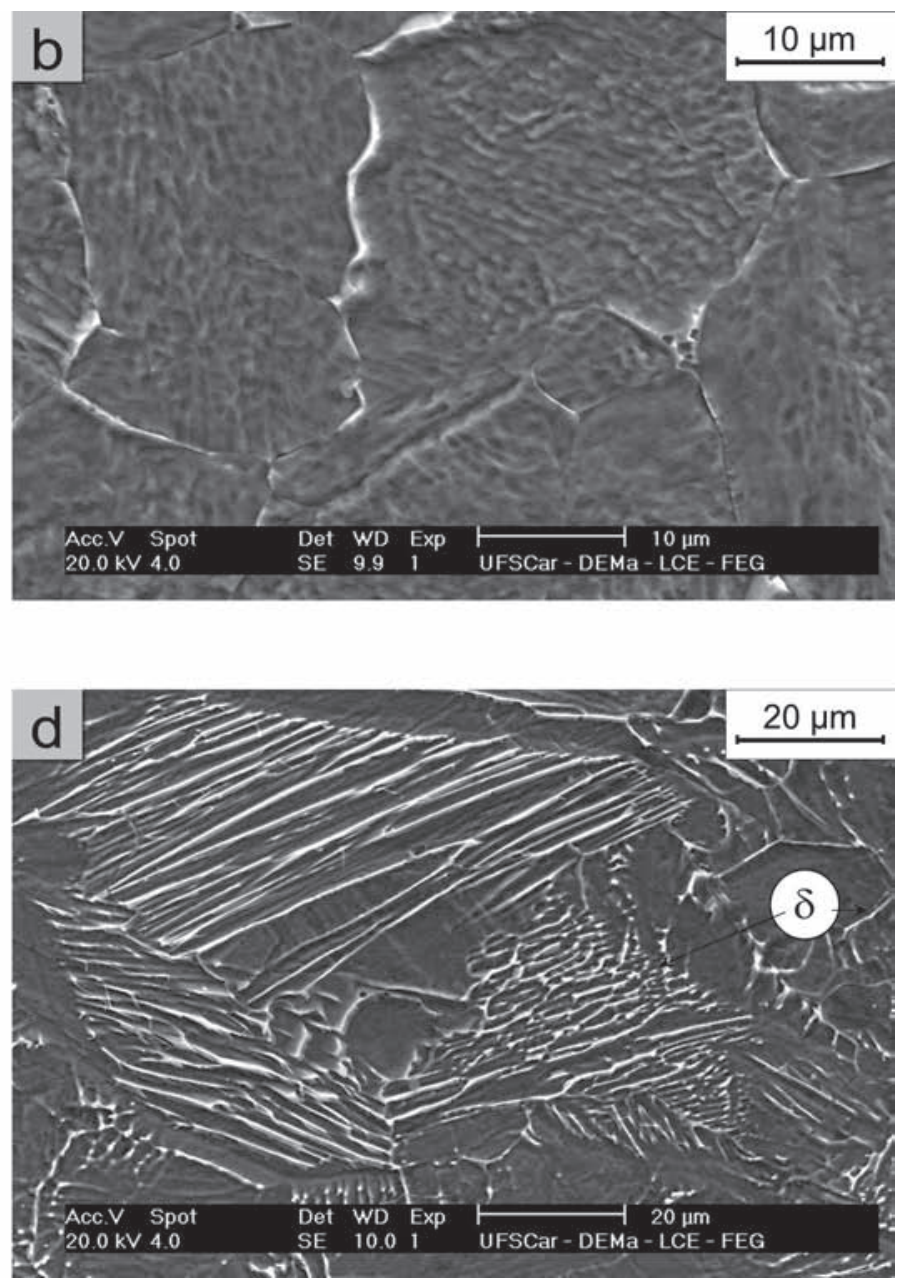

Figura 6. Imagens de MEV do aspecto superficial das diferentes regiões da solda SFR após o teste de DL-EPR: (a) MB; (b) AC; (c) ZTA e (d) ZTMA. 

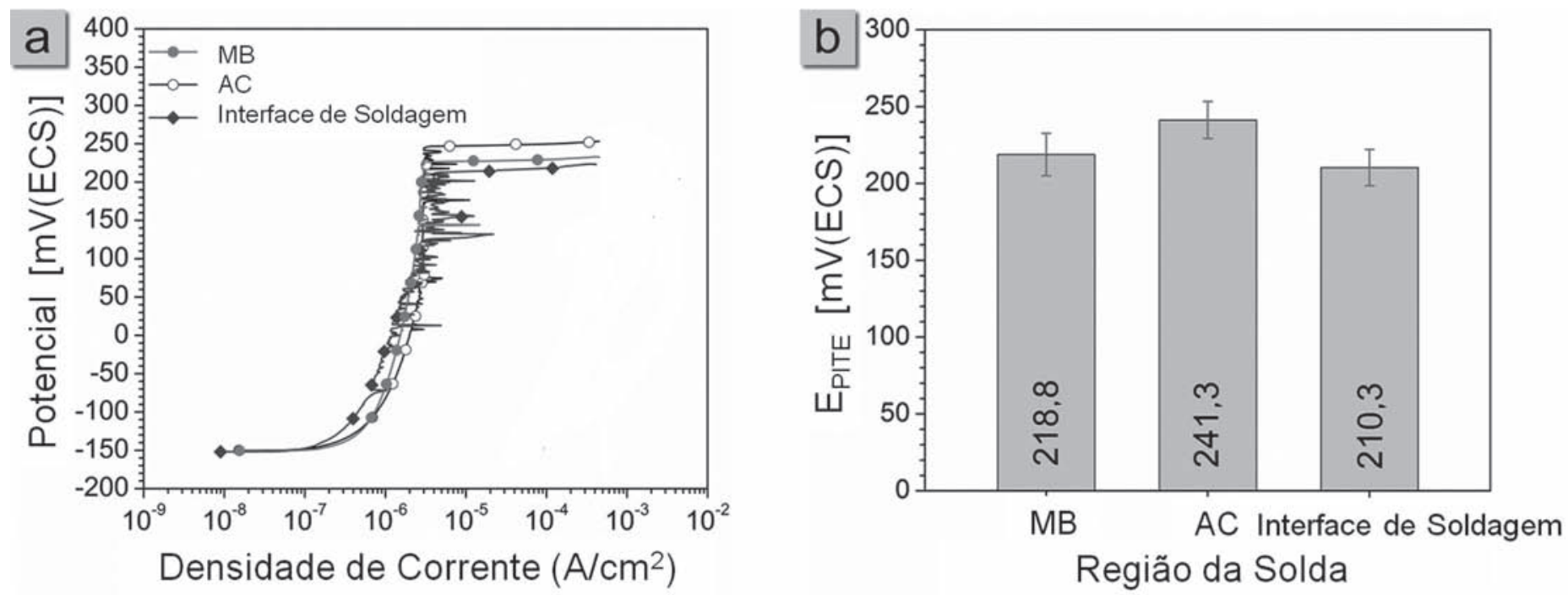

Figura 7. Curvas de polarização anódica em solução de 3,5 \% de NaCl e (b) potencial de pites das diferentes regiões da solda SFR.
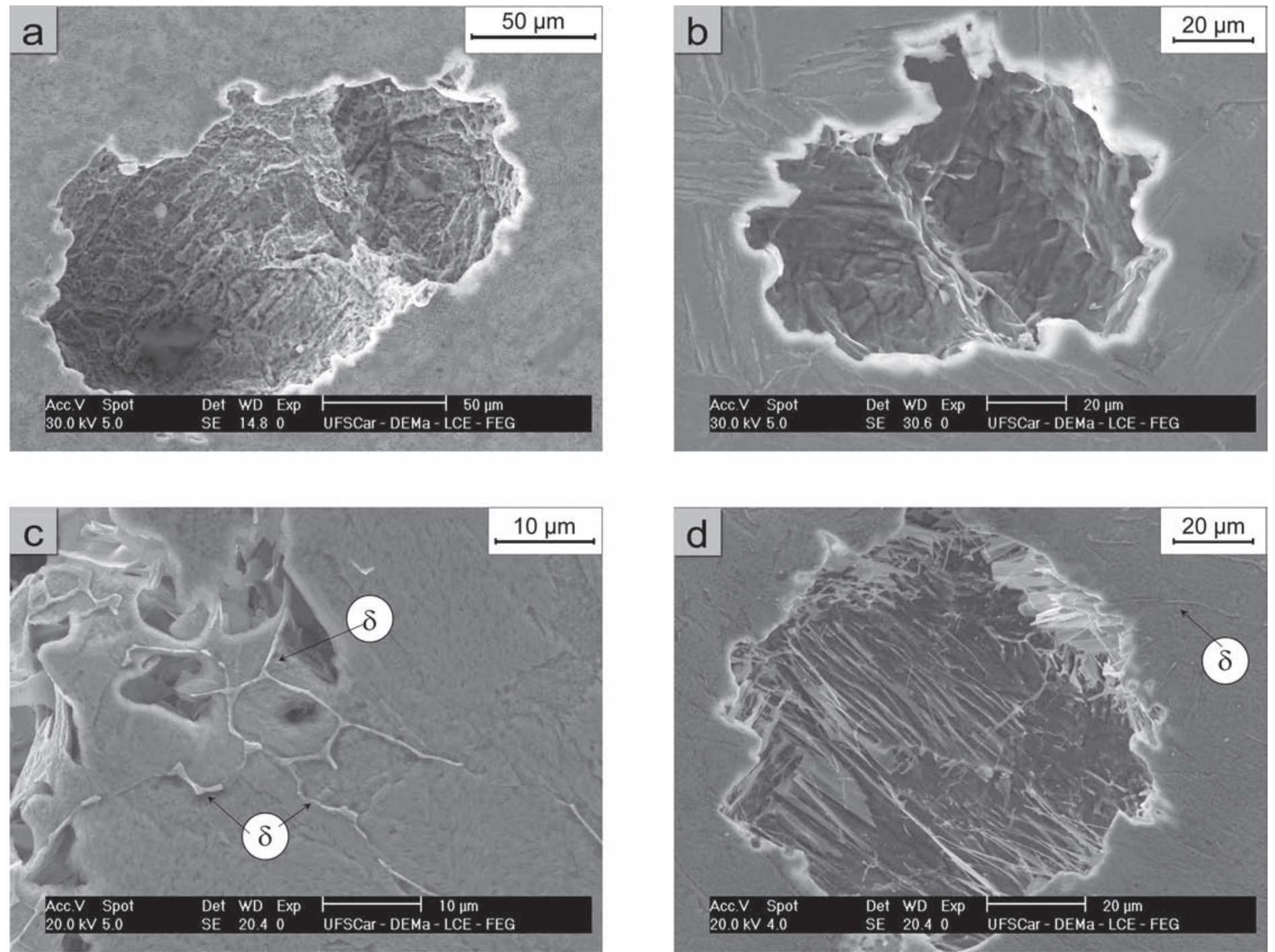

Figura 8. Morfologia típica dos pites na superfície das amostras após o ensaio de polarização anódica em solução 3,5\% de $\mathrm{NaCl}$ : (a) MB; (b) AC; (c) ZTA e (d) ZTMA. 
está em bom acordo com as análises de MEV após as medidas de DL-EPR [Figura 6 (c)] e sugere a formação de regiões empobrecidas em Cr pela precipitação de carbonetos de $\mathrm{Cr}$ nos contornos da ferrita- $\delta$ [18-20]. Outro mecanismo plausível é que a formação de ferrita- $\delta$ resulta em uma diminuição em solução sólida dos teores de $\mathrm{Cr}$ e Mo na martensita adjacente [21]. Moon e colaboradores [21] estudaram a ZTA de um aço inoxidável $\mathrm{Fe}-18 \mathrm{Cr}-10 \mathrm{Mn}-0.33 \mathrm{~N}-0,03 \mathrm{C}$ e verificaram que a formação de zonas empobrecidas em $\mathrm{Cr}$ ao redor das ilhas de ferrita- $\delta$ são locais favoráveis para a iniciação da corrosão por pites. A formação dessas zonas empobrecidas em Cr na austenita adjacente à ferrita- $\delta$ promoveu uma redução do $\mathrm{E}_{\text {PITE }}$ da ZTA do aço inoxidável Fe-18Cr-10Mn-0.33N-0,03 C em relação à estrutura do seu MB. Na Figura 8 (d), também pode ser notado que, devido ao maior teor de $\mathrm{Cr}$ e Mo, a ferrita- $\delta$ não é tão dissolvida quanto a matriz martensítica durante o progresso da corrosão por pites, fato que resulta em uma estrutura de ferrita- $\delta$ semi-contínua dentro do pite.

Embora um valor muito alto de $I_{r} I_{a}(54,22)$ tenha sido medido para a amostra do $\mathrm{MB}$, indicando um alto grau de empobrecimento em $\mathrm{Cr}$, a redução da resistência à corrosão localizada foi muito pequena. Isso indica que a precipitação de carbonetos de $\mathrm{Cr}$ que ocorre durante o tratamento térmico de revenimento e o subsequente empobrecimento em $\mathrm{Cr}$ na estrutura revenida do MB causa apenas uma pequena redução na resistência à corrosão localizada em ambiente de cloretos $\left[\mathrm{E}_{\mathrm{PTTE}}=\right.$ $218,8 \mathrm{mV}$ (ECS)]. Por outro lado, um valor menor de $\mathrm{E}_{\text {PITE }}$ [210,3 $\mathrm{mV}$ (SCE)] foi medido para a amostra extraída da interface de soldagem, que apresentou um valor muito baixo de $I_{r} I_{a}(0,18)$, ou seja, um baixo grau de empobrecimento em Cr. Entretanto, a análise microestrutural desta amostra após o teste DL-EPR indicou um ataque seletivo pronunciado nos contornos de fase martensita/ferrita- $\delta$ [Figura 6 (d)], indicando que a formação de ferrita- $\delta$ na ZTA do AISM leva a um empobrecimento em $\mathrm{Cr}$ na matriz martensítica adjacente.

Uma explicação plausível para a aparente falta de boa correlação entre os resultados das medidas de DL-EPR e dos ensaios de polarização anódica em solução 3,5\% de $\mathrm{NaCl}$ para as amostras MB e interface de soldagem pode ser elaborada da seguinte forma. A relação $I_{r} I_{a}$ medida a partir dos ensaios de DL-EPR depende da fração total das regiões empobrecidas em $\mathrm{Cr}$, que no caso da estrutura revenida da região do MB é muito maior do que a da interface de soldagem, como pode ser visto pelo aspecto superficial das amostras após o ensaio de DL-EPR [Figura 6]. No entanto, deve ser levado em conta que a corrosão por pites se inicia nas regiões que contêm o menor teor de $\mathrm{Cr}$ (dentro da região empobrecida em Cr) e o valor de $\mathrm{E}_{\mathrm{PITE}}$ depende da iniciação. Portanto, a redução do valor de $E_{\text {PITE }}$ da interface de soldagem em relação ao MB provavelmente ocorre porque o teor mínimo de $\mathrm{Cr}$ presente nos contornos de fase martensita/ ferrita- $\delta$ na interface de soldagem é inferior ao das regiões adjacentes aos precipitados ricos em $\mathrm{Cr}$ no $\mathrm{MB}$, embora estas últimas estejam presentes em uma fração muito maior.

\section{Conclusões}

Os experimentos realizados nesse trabalho permitiram concluir que:

1. A precipitação generalizada de carbonetos de Cr que está presente na estrutura revenida do MB resulta em um elevado grau de empobrecimento em $\mathrm{Cr}\left(I_{r} / I_{a}=54,22\right)$, quando medido pelo teste de DL-EPR;

2. Devido à alteração da microestrutura promovida pelo ciclo termomecânico da soldagem SFR, as regiões do AC e da interface de soldagem apresentam um baixo grau de empobrecimento em $\mathrm{Cr}\left(I_{r} / I_{a}<1\right)$;

3. Embora nenhum grau significativo de empobrecimento em Cr tenha sido detectado por DL-EPR na região da interface de soldagem, uma dissolução pronunciada foi observada entre os contornos de fase martensita/ferrita- $\delta$ após o teste de DLEPR;

4. Uma diminuição da resistência à corrosão por pites foi observada na interface de soldagem devido à formação de ferrita- $\delta$;

5. A precipitação de carbonetos de Cr promovida pelo tratamento térmico de revenimento na estrutura do MB não causa uma significativa diminuição da resistência à corrosão por pites;

6. As alterações microestruturais promovidas pelo ciclo termomecânico da soldagem SFR na região do AC resultaram em um aumento da resistência à corrosão localizada em relação à região do MB.

\section{Agradecimentos}

Os autores agradecem à Fundação de Amparo à Pesquisa do Estado de São Paulo - FAPESP (processo: 12/16113-6) pelo suporte financeiro e auxílio imprescindíveis para realização desse trabalho.

\section{Referências Bibliográficas}

[1] SMITH, L., CELANT M. Martensitic stainless steels in context. In: SUPERMARTENSITIC STAINLESS STEELS 2002, 2002, Bruxelas. Proceedings... Bruxelas: Belgium Welding Institute, 2002. p.14-20.

[2] ANSELMO, N. et al., Corrosion behavior of supermartensitic stainless steel in aerated and $\mathrm{CO}_{2}$-saturated synthetic seawater. Materials Science and Engineering A, v. 428, p. 73-79, 2006.

[3] RIBEIRO, C.; SANTOS, J.F.; ALCÂNTARA, N.G. Os novos aços inoxidáveis supermartensíticos e sua soldabilidade. Soldagem e Inspeção, v. 9, p. 104-112, 2004.

[4] AQUINO, J.M., DELLA ROVERE, C.A., KURI, S.E. Intergranular corrosion susceptibility in supermartensitic stainless steel weldments. Corrosion Science, v. 51, p. 23162323, 2009.

[5] DELLA ROVERE, C.A. et al., Microstructural and mechanical characterization of radial friction welded supermartensitic stainless steel joints. Materials Science and Engineering A, v. 586, p. 86-92, 2013.

[6] DELLA ROVERE, C.A. et al., Local mechanical properties of radial friction welded supermartensitic stainless steel pipes. Materials and Design, v. 56, p. 423-427, 2014.

[7] NICHOLAS, E.D. Radial friction welding. Welding Journal, 
v. 62, p. 17-29, 1983.

[8] LUTTEROTTI, L. et al., Texture, residual stress and structural analysis of thin films using a combined X-ray analysis. Thin Solid Films, v. 450, p. 34-41, 2004.

[9] CÍHAL, V., STEFEC, R. On the development of the electrochemical potentiokinetic method. Electrochimica Acta, v. 46, p. 3867-3877, 2001.

[10] PEREDA, M.D. et al., Microelectrochemical corrosion study of super martensitic welds in chloride-containing media. Corrosion Science, v. 53, p. 3934-3941, 2011.

[11] SILVA, G.F. et al., Influence of heat treatments on toughness and sensitization of a Ti-alloyed supermartensitic stainless steel. Journal of Materials Science, v. 46, p. 7737-7744, 2011.

[12] HENKE, S.L. et al., Desenvolvimento da ferrita delta na solda e ZTA resultante de soldagem plasma pulsada em um aço inoxidável supermartensítico. Soldagem e Inspeção, v.18, n.1, p. 57-63, 2013.

[13] TRUMAN, J.E. Corrosion resistance of 13\% chromium steels as influenced by tempering treatments. British Corrosion Journal, v. 11, n. 2, p. 92-96, 1976.

[14] FALLEIROS, N.A.; MAGRI, M.; FALLEIROS, I.G.S. Intergranular corrosion in a martensitic stainless steel detected by electrochemical test. Corrosion, v. 55, p. 769-777, 1999.

[15] FOLKHARD, E. Welding metallurgy of stainless steels. Nova Iorque: Springer-Verlag/Wien, 1988.

[16] PICKERING, F.B. The Metallurgical Evolution of Stainless Steels. Londres: American Society for Metals, 1979.

[17] VODARED, V.; TVRDY, M.; KORCAK, A. Heat treatment of supermartensitic steels. Inzynieria Materialowa, v. 5, p. 939941, 2001.

[18] HARA, T., ASAHI, H. Effect of $\delta$-ferrite on Sulfide stress cracking in a low carbon 13 mass \% chromium steel. ISIJ international, v. 40, n. 11, p, 1134-1141, 2000.

[19] SMITH, L. Sensitization of martensitic stainless steels. Materials Performance, p. 55-56, dez., 2002.

[20] LADANOVA, E., SOLBERG, J. K., ROGNE, T. Carbide precipitation in HAZ of multipass welds in titanium containing and titanium free supermartensitic stainless steels Part 1 proposed precipitation mechanisms. Corrosion Engineering, Science and Technology, v. 41, p. 143-151, 2006.

[21] MOON, J. et al., Different aspect of pitting corrosion and interphase corrosion in the weld heat-affected zone of highnitrogen $\mathrm{Fe}-18 \mathrm{Cr}-10 \mathrm{Mn}-\mathrm{N}$ steel. Materials Chemistry and Physics, v.142, p. 556-563, 2013. 